\title{
O TRIBUNAL DO COMÉRCIO NO APARATO ESTATAL DO IMPÉRIO: JULGAMENTO E ENCENAÇÃO
}
EL TRIBUNAL DE COMERCIO EN EL APARATO ESTATAL DEL IMPERIO: JUICIO Y ESCENIFICACIÓN
THE CHAMBER OF COMMERCE AND THE STATE APPARATUS OF THE EMPIRE: TRIALS AND STAGING

\section{LE TRIBUNAL DE COMMERCE DANS L'APPAREIL D'ÉTAT IMPÉRIAL : JUGEMENT ET MISE EN SCÈNE}

DOI: 10.5533/1984-2503-20124202

Edson Alvisi Neves ${ }^{1}$

\section{RESUMO}

O presente trabalho visa estudar as funções jurisdicionais realizadas pelo Tribunal do Comércio no Império do Brasil, com um mapeamento quantitativo a partir dos documentos encontrados e as ligações decorrentes ou incidentes desta atividade com as instituições do império, principalmente a influência da imprensa e o seu uso como determinante de alguns resultados em julgamentos oficiais.

Palavras-chave: julgamentos; instituições; influências.

\section{RESUMEN}

Este trabajo pretende estudiar las funciones jurisdiccionales realizadas por el Tribunal de Comercio en el Imperio de Brasil, con un levantamiento cuantitativo a partir de los documentos encontrados y las relaciones decurrentes o incidentes de esta actividad con las otras instituciones del imperio, sobre todo la influencia de la prensa y su utilización como determinante de algunos resultados en juicios oficiales.

Palabras-clave: juicios; instituciones; influencias.

\footnotetext{
${ }^{1}$ Professor Titular e Diretor da Faculdade de Direito da Universidade Federal Fluminense. E-mail: ealvisi@ig.com.br
} 


\section{ABSTRACT}

The present work aims to study the judicial role of the Chamber of Commerce in the Empire of Brazil, by means of a quantitative mapping of the documents collected, and the resulting connections or incidental links with the other institutions of the empire, especially regarding the influence of the press and its role in determining some of the results of official rulings.

Key words: trials; institutions; influences.

\section{RÉSUMÉ}

Le présent travail vise à étudier les fonctions juridictionnelles exercées par le Tribunal de commerce dans le Brésil impérial, avec une cartographie quantitative réalisée à partir des documents retrouvés, et les liens découlant de cette activité avec les autres institutions de l'Empire, principalement en ce qui concerne l'influence de la presse et son usage déterminant dans le résultat de certains jugements officiels.

Mots-clés : jugements ; institutions ; influences.

\section{As atividades jurisdicionais do Tribunal do Comércio da Corte ${ }^{2}$}

Duas funções precípuas marcavam a atividade do Tribunal do Comércio, uma de cunho administrativo, alvo do trabalho de Rubenita Vieira (1985), que se traduzia na execução da matricula dos comerciantes e dos agentes auxiliares do comércio, e na autenticação dos livros e documentos relativos às atividades do comércio. A outra função, objeto de nosso trabalho, é a jurisdicional. Esta segunda função é dividida em duas fases, a primeira incide da instalação até a reforma que atingiu o referido tribunal e, determinada pelo Decreto n. 1.597 de 1․ de maio de 1855, portanto de 1851 a 1855, em cujo período o tribunal funcionava como órgão de primeira instância, estando os recursos destinados ao julgamento pelo Tribunal da Relação.

O segundo período do tribunal, de 1855 até a sua extinção em 1876, é marcado por uma atuação como órgão de instância recursal para os processos que tinham como objeto os atos de comércio, assim considerados os elencados no artigo 19 do Regulamento 737 e os (atos) a eles equiparados. Excetuando-se os processos de

\footnotetext{
${ }^{2}$ Este trabalho desenvolve reflexão baseada em fonte documental levantada pela pesquisa realizada para a tese de doutorado.
} 
falências, cuja competência para processamento em primeiro grau continuou a pertencer ao dito tribunal e os recursos originados nestes dirigidos ao Tribunal da Relação. Os recursos pertinentes aos processos comerciais foram os descritos na parte terceira do regulamento 737 e compreendiam a apelação, os agravos de petição e de instrumento e o recurso de revista.

As apelações ${ }^{3}$ compreendem o mecanismo de revisão das sentenças, considerado como o procedimento para o atendimento do chamado duplo grau de jurisdição, que se assenta como um direito dos jurisdicionados e inerente à própria natureza humana que não se contenta com uma decisão contrária aos seus interesses e sempre que possível, buscam uma nova opinião. Técnica que leva a um outro princípio de que este segundo julgamento revisor deve ser realizado sempre em colegiado e por juízes mais experientes.

Com relação às apelações julgadas no Tribunal do Comércio da Corte do Brasil no período imperial, só foi encontrado o livro relativo às anotações do período de 1862 a 1866, onde se apurou julgamento de 1.149 apelações para o período, o que corresponde a uma média de 229,8 apelações por ano ou 16,41 ao mês, correspondendo a uma atividade jurisdicional intensa ${ }^{4}$, inclusive, porque a previsibilidade ${ }^{5}$ inicial de sessões limitava-se a realização em dois dias da semana as segundas e quintas-feiras.

TABELA 1

Apelações no Tribunal do Comércio da Corte brasileira (1862-1866)

\begin{tabular}{|l|r|r|r|r|r|r|r|r|r|r|r|r|r|}
\hline ANO & TOTAIS & JAN & FEV & MAR & ABR & MAI & JUN & JUL & AGO & SET & OUT & NOV & DEZ \\
\hline $\mathbf{1 8 6 2}$ & 190 & 08 & 17 & 11 & 14 & 13 & 08 & 14 & 11 & 18 & 35 & 21 & 20 \\
\hline $\mathbf{1 8 6 3}$ & 212 & 04 & 12 & 17 & 15 & 13 & 20 & 16 & 23 & 19 & 22 & 26 & 25 \\
\hline $\mathbf{1 8 6 4}$ & 257 & 09 & 20 & 21 & 17 & 17 & 15 & 27 & 23 & 17 & 17 & 32 & 42 \\
\hline $\mathbf{1 8 6 5}$ & 243 & 10 & 21 & 27 & 12 & 28 & 25 & 17 & 09 & 28 & 24 & 17 & 25 \\
\hline $\mathbf{1 8 6 6}$ & 247 & 07 & 14 & 23 & 13 & 22 & 18 & 29 & 33 & 17 & 15 & 25 & 31 \\
\hline TOTAL & 1149 & 38 & 84 & 99 & & 93 & 86 & 103 & 99 & & 113 & 121 & \\
& & & & & 71 & & & & & 99 & & & 143 \\
\hline
\end{tabular}

Fonte: AN, Código do fundo MX. Seção de guarda: SDJ, SDJ031, os seguintes livros:

Livro de entrada de feitos na secretaria (1855-1867),

Guia de andamento de apelações comerciais embargo e registros (1855-1860),

Guia de andamento de apelações (1864-1866),

Livro de inventário dos autos de apelações (1855).

\footnotetext{
${ }^{3}$ Regulamento 737, art. 646 a 664.

${ }_{5}^{4}$ Arno Welling indica que o Tribunal da Relação da Corte julgou 114 apelações no período de 1763 a 1808.

${ }^{5}$ Regulamento n. 738 de 1850, art. $1^{\circ}$. - Os Tribunaes do Commercio terão sessões ordinárias às segundas e quintas feiras, quando não forem dias santos de guarda ou feriados, e sendo-o, no dia seguinte; e as extraordinárias que os Presidentes julgarem necessárias. Se algum Membro do Tribunal não puder comparecer, participará o seu impedimento ao Tribunal, por via do Secretário.
} 
GRÁFICO 1

Entrada de apelações por ano, para o período de 1862-1866

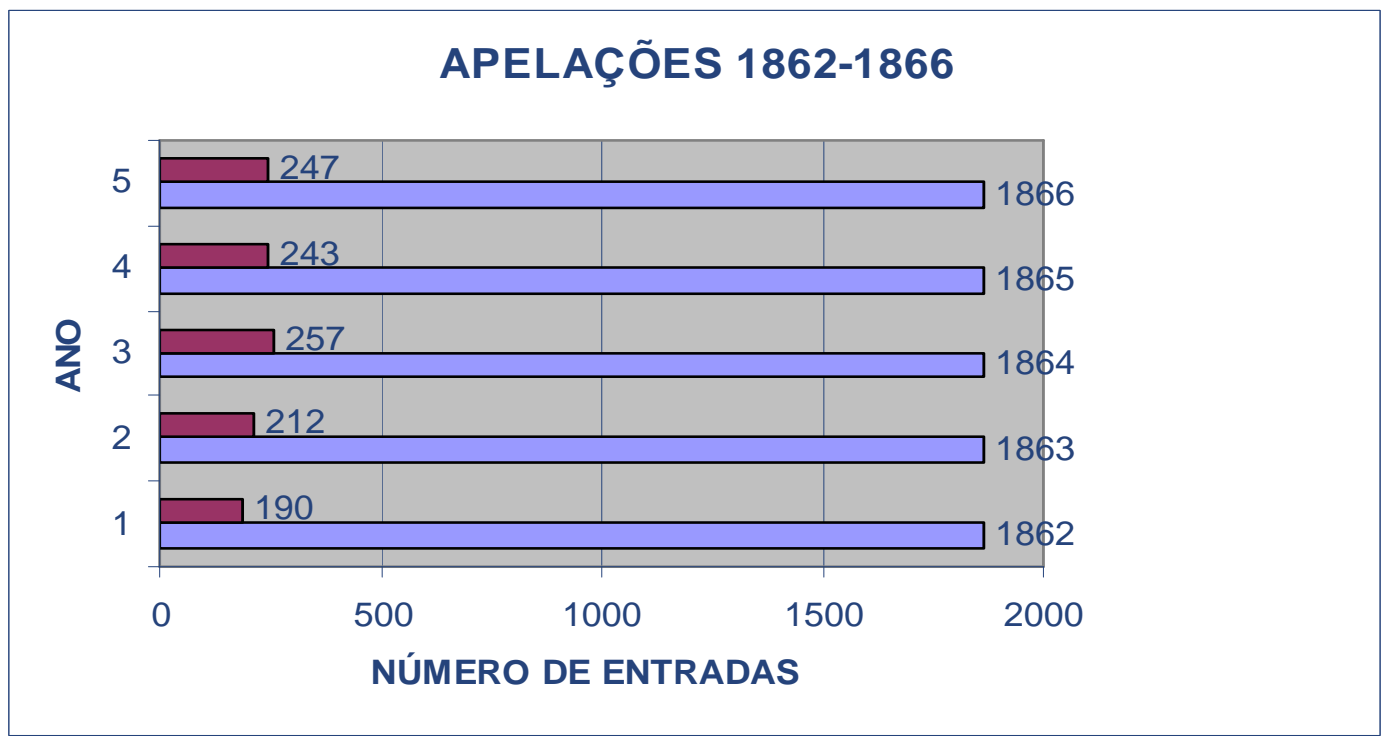

GRÁFICO 2

Entrada de apelações por mês para o período de 1862 a 1866

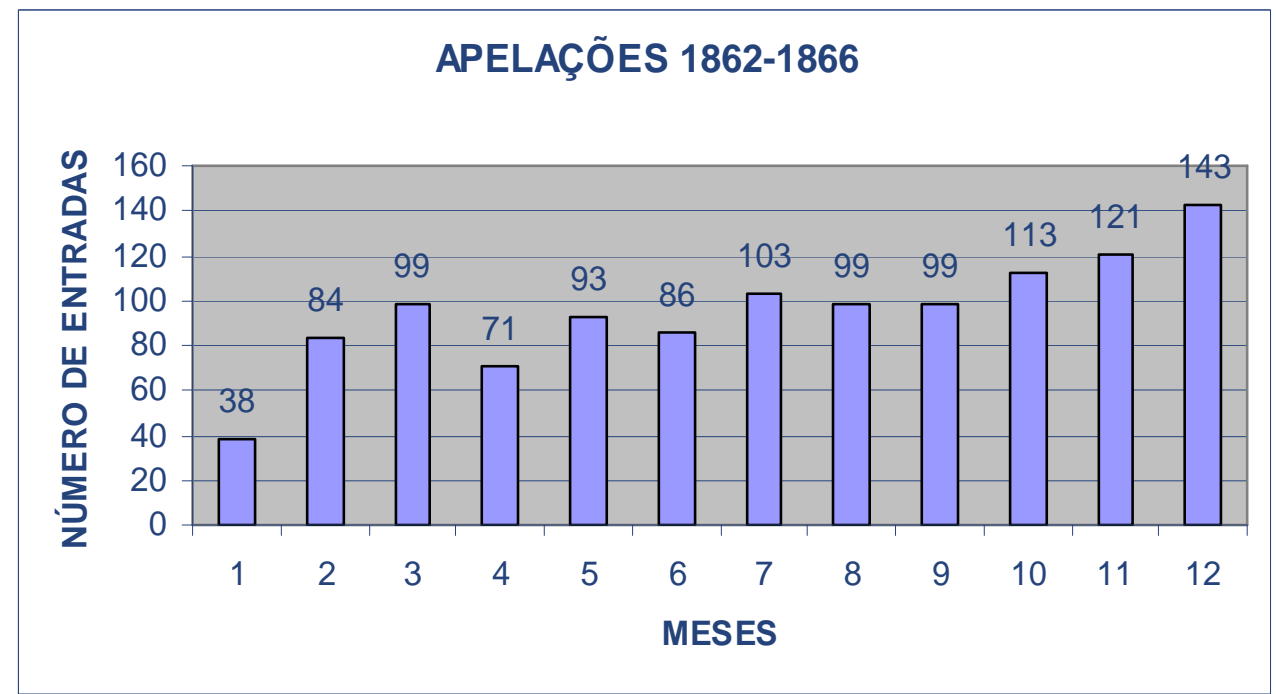

Outro recurso atribuído ao tribunal foi o agravo de petição (art. 668 a 671), que tinha mesma função que a apelação, porém destinados aos processos findos com sentença sem o julgamento do mérito ou nos processos que não houve dilação probatória em razão do procedimento sumário, caso da Assinação de dez dias ou do Seguro. Também, das decisões com efeitos meramente homologatórios, caso da aprovação de contas, das decisões sobre: liquidação, exibição, habilitação, deserção e julgamento de 
advogados. Mais uma vez, na documentação encontrada que se refere unicamente ao período de 1861-1866, podemos verificar uma pauta cheia, com 1.071 julgados de agravo de petição para o período, com uma média de 178,5 julgamentos por ano ou 14,87 por mês, conforme indica a tabela abaixo:

TABELA 2

Agravo de petição no Tribunal do Comércio da Corte brasileira (1861-1866)

\begin{tabular}{|c|c|c|c|c|c|c|c|c|c|c|c|c|c|}
\hline ANO & TOTAIS & JAN & FEV & MAR & ABR & MAI & JUN & JUL & AGO & SET & OUT & NOV & DEZ \\
\hline 1861 & 205 & 01 & 09 & 14 & 07 & 17 & 21 & 20 & 29 & 20 & 26 & 19 & 22 \\
\hline 1862 & 155 & 02 & 14 & 17 & 14 & 14 & 10 & 17 & 23 & 14 & 13 & $\mathrm{~S} / \mathrm{E}$ & 17 \\
\hline 1863 & 183 & 04 & 09 & 19 & 10 & 24 & 22 & 17 & 16 & 24 & 21 & S/E & 17 \\
\hline 1864 & 201 & 04 & 23 & 35 & 12 & 13 & 28 & 18 & 26 & 10 & 17 & $\mathrm{~S} / \mathrm{E}$ & 15 \\
\hline 1865 & 179 & 02 & 09 & 19 & 14 & 18 & 10 & 13 & 27 & 22 & 25 & $S / E$ & 20 \\
\hline 1866 & 148 & $\mathrm{~S} / \mathrm{E}$ & 08 & 24 & 08 & 10 & 15 & 21 & 10 & 13 & 21 & $S / E$ & 18 \\
\hline TOTAL & 1071 & 13 & 72 & 128 & 65 & 96 & 106 & 106 & 131 & 103 & 123 & 19 & 109 \\
\hline
\end{tabular}

Fonte: AN, Código do fundo MX. Seção de guarda: SDJ, SDJ031, os seguintes livros: Livro de entrada de feitos na secretaria (1855-1867),

Registro de entrada de autos (1861-1866)

GRÁFICO 3

Entrada de agravo de petição por ano para o período de 1861-1866

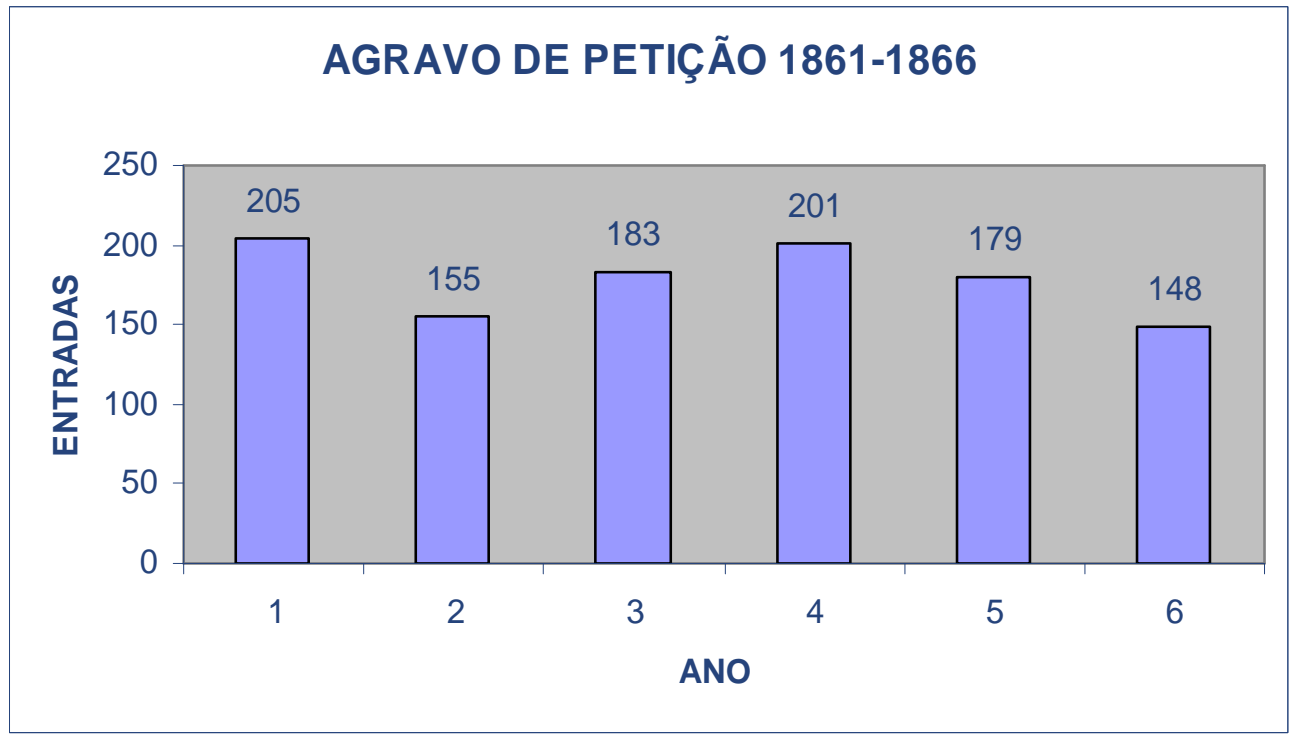




\section{GRÁFICO 4}

Entrada de agravo de petição por mês para o período de 1861-1866

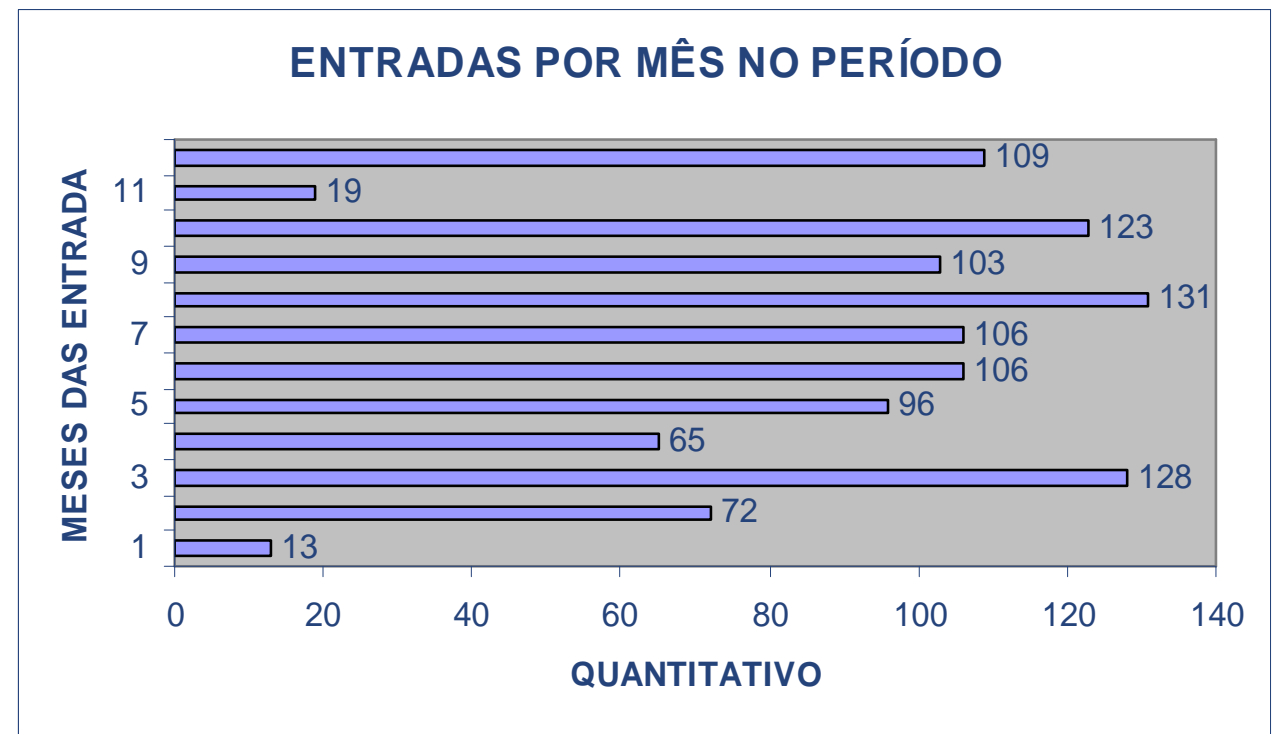

A outra modalidade de agravo julgado pelo tribunal era o agravo de instrumento, recurso destinado a revisão de decisões que não se configuram como sentença por não concluir procedimentos, mas que atingia os interesses da parte e segundo os art. 669 do Regulamento 737, para os casos de despachos em geral, que determina prisão, vistas aos autos, que denega prisão e demais decisões interlocutórias. As anotações encontradas também se referem ao período de 1861-1866 e apresentaram um número menor de recursos de agravo em comparação aos dois abordados anteriormente, foram apenas 90 nos 6 anos, uma média de 15 por ano ou 1,2 ao mês, conforme tabela:

TABELA 3

Agravo de instrumento no Tribunal do Comércio da Corte brasileira (1861-1866)

\begin{tabular}{|l|r|r|r|r|r|r|r|r|r|r|r|r|r|}
\hline ANO & JAN & FEV & MAR & ABR & MAI & JUN & JUL & AGO & SET & OUT & NOV & DEZ & TOTAIS \\
\hline 1861 & & & & & 1 & & & & & 2 & & 2 & 5 \\
\hline 1862 & 1 & & & 1 & 1 & 1 & & & 2 & 2 & 1 & 1 & 10 \\
\hline 1863 & & & 2 & 3 & & & 3 & 3 & 1 & 1 & 2 & 2 & 17 \\
\hline 1864 & & 1 & 3 & & 2 & 3 & 4 & & 2 & 1 & 2 & 1 & 19 \\
\hline 1865 & 1 & & 1 & 2 & 3 & & 7 & 5 & 2 & 4 & 1 & & 26 \\
\hline 1866 & & & 1 & & & 1 & 3 & 2 & 2 & 1 & 2 & 1 & 13 \\
\hline TOTAIS & 2 & 1 & 7 & 6 & 7 & 5 & 17 & 10 & 9 & 11 & 8 & 7 & 90 \\
\hline
\end{tabular}

Fonte: AN, Código do fundo MX. Seção de guarda: SDJ, SDJ031, os seguintes livros: Livro de entrada de feitos na secretaria (1855-1867), Registro de entrada de autos (1861-1866) 


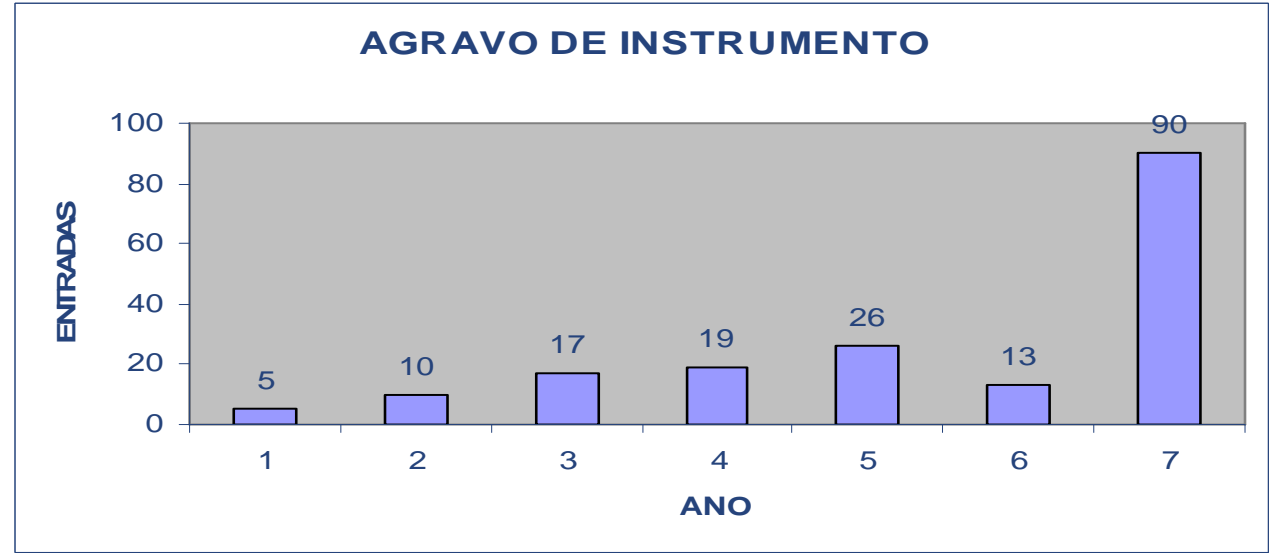

O Regulamento 737 previa o recurso de Revista contra as decisões proferidas no Tribunal da Relação, como um recurso destinado ao Supremo Tribunal de Justiça nas causas que excedessem a $2.000 \$ 000$ (art. 665 a 667), mas com a nova configuração do Tribunal do Comércio, atribuída com o Decreto n. 1.597 de 1855, a Revista passou a ter cabimento nas causas excedentes de $5.000 \$ 000$ e a ter o julgamento de admissibilidade realizado pelos próprios Tribunais do Comércio (art. 82). Os Recursos admitidos pelos tribunais da Bahia, Pernambuco e Maranhão eram julgados pelo tribunal da Corte (art. 83), fixando o tribunal da Corte como uma espécie de supervisor, normalmente, posição atribuída aos tribunais superiores ou mais especificamente, o Supremo Tribunal de Justiça. Portanto, o tribunal da Corte assume uma posição que coloca o seu presidente próximo ao Supremo Magistrado do Comércio português.

Os Livros de Entrada de Feitos na secretaria e de Registro de entrada de autos se referem ao período já mencionado de 1861-1866, no qual foram encontrados os registros referentes a 210 Revistas negadas. Para as revistas concedidas a documentação só mantinha anotações do período de 1861-1865, com total de 40 concedidas. As Revistas oriundas de outros tribunais só foram encontradas as anotações referentes aos anos de 1864, 1865 e 1866, nas quais se observam os julgamentos relativos a 18 Revistas, sendo originadas: 1 do Maranhão, 2 da Bahia e 15 de Pernambuco, como se demonstra nas tabelas e gráficos abaixo: 
TABELA 4

Revistas negadas

\begin{tabular}{|l|r|r|r|r|r|r|r|r|r|r|r|r|r|}
\hline ANO & JAN & FEV & MAR & ABR & MAI & JUN & JUL & AGO & SET & OUT & NOV & DEZ & TOTAIS \\
\hline $\mathbf{1 8 6 1}$ & & 1 & 3 & 5 & & 3 & 3 & 6 & 3 & 3 & 4 & 6 & 37 \\
\hline $\mathbf{1 8 6 2}$ & & 2 & 2 & 1 & 4 & & 2 & 2 & 3 & & 4 & 4 & 24 \\
\hline $\mathbf{1 8 6 3}$ & & & 3 & & 5 & 2 & & 2 & 4 & 5 & 1 & & 22 \\
\hline $\mathbf{1 8 6 4}$ & & 2 & 3 & & 6 & 3 & 4 & 4 & 7 & 3 & 4 & 1 & 37 \\
\hline $\mathbf{1 8 6 5}$ & & & 6 & & 5 & 6 & & 3 & 4 & 2 & 3 & 3 & 32 \\
\hline $\mathbf{1 8 6 6}$ & & 1 & 5 & 4 & 2 & 9 & 4 & 6 & 9 & 2 & 12 & 4 & 58 \\
\hline TOTAIS & & 6 & 22 & 10 & 22 & 23 & 13 & 23 & 30 & 15 & 28 & 18 & 210 \\
\hline
\end{tabular}

Fonte: AN, Código do fundo MX. Seção de guarda: SDJ, SDJ031, os seguintes livros:

Livro de entrada de feitos na secretaria (1855-1867),

Registro de entrada de autos (1861-1866)

GRÁFICO 6

Revistas negadas

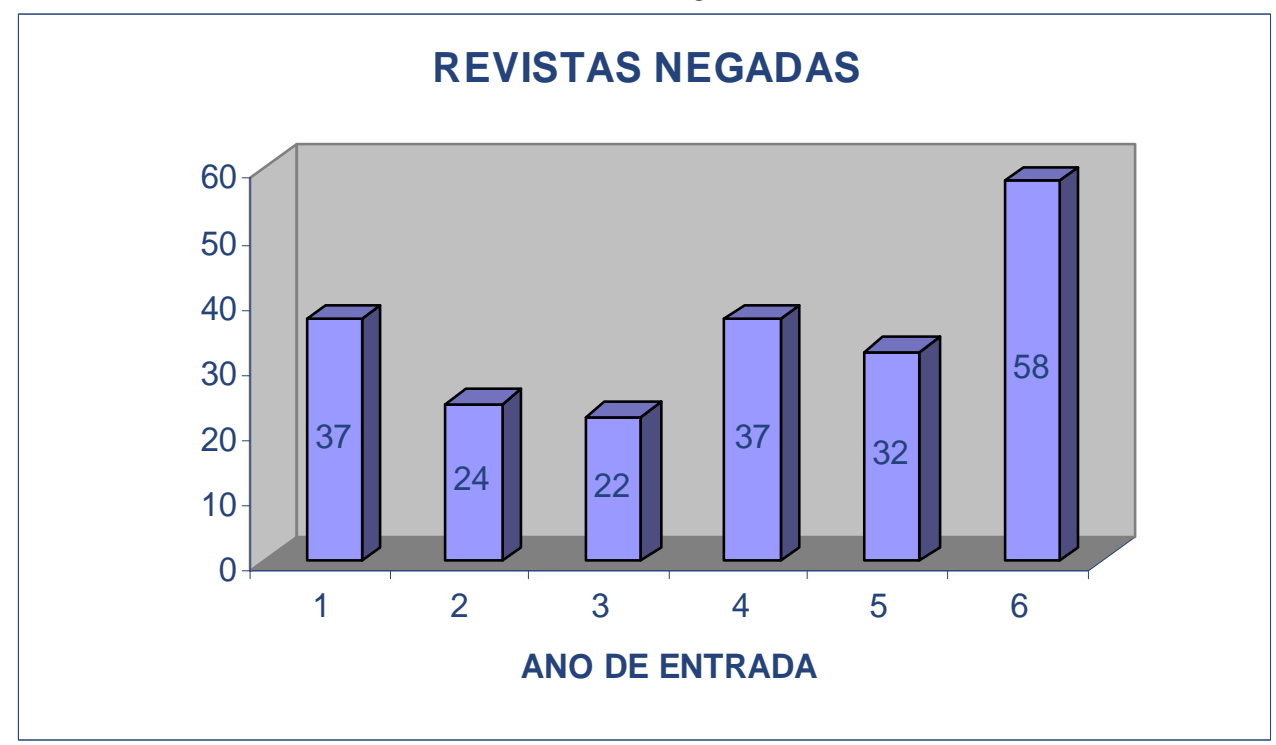

TABELA 5

Revistas concedidas, por meses e para o período de 1861-1865.

\begin{tabular}{|c|c|c|c|c|c|c|c|c|c|c|c|c|c|}
\hline ANO & JAN & FEV & MAR & ABR & MAI & JUN & JUL & AGO & SET & OUT & NOV & DEZ & TOTAIS \\
\hline 1861 & & 1 & & & & & & & 1 & & 1 & & 3 \\
\hline 1862 & 1 & 1 & & & & 1 & 2 & & & 1 & 2 & 13 & 21 \\
\hline 1863 & 3 & & 1 & & 1 & & 1 & 2 & 1 & 1 & & & 10 \\
\hline 1864 & & & 1 & & & & 1 & & 1 & & & & 3 \\
\hline 1865 & 1 & & 1 & & & & 1 & & & & & & 3 \\
\hline TOTAIS & 5 & 2 & 3 & & 1 & 1 & 5 & 2 & 3 & 2 & 3 & 13 & 40 \\
\hline
\end{tabular}

Fonte: AN, Código do fundo MX. Seção de guarda: SDJ, SDJ031, os seguintes livros:

Livro de entrada de feitos na secretaria (1855-1867),

Registro de entrada de autos (1861-1866). 
Revistas oriundas de outros tribunais e concedidas, por ano, para o período de 1864-1866.

\begin{tabular}{|l|l|l|l|r|r|r|r|r|r|r|r|r|r|}
\hline ANO & JAN & FEV & MAR & ABR & MAI & JUN & JUL & AGO & SET & OUT & NOV & DEZ & TOTAIS \\
\hline $\mathbf{1 8 6 4}$ & & & & 1 & 1 & 1 & & 1 & & & 1 & & 5 \\
\hline $\mathbf{1 8 6 5}$ & & & & 1 & & & & 1 & 1 & & 3 & & 6 \\
\hline $\mathbf{1 8 6 6}$ & & & & 4 & & 2 & 1 & & & 1 & 1 & 2 & 11 \\
\hline TOTAIS & & & & 6 & 1 & 3 & 1 & 2 & 1 & 1 & 5 & 2 & 22 \\
\hline
\end{tabular}

Fonte: AN, Código do fundo MX. Seção de guarda: SDJ, SDJ031, os seguintes livros: Livro de entrada de feitos na secretaria (1855-1867), Registro de entrada de autos (1861-1866).

TABELA 7

Revistas oriundas de outros tribunais, por estado de origem, para o período de 1864-1866.

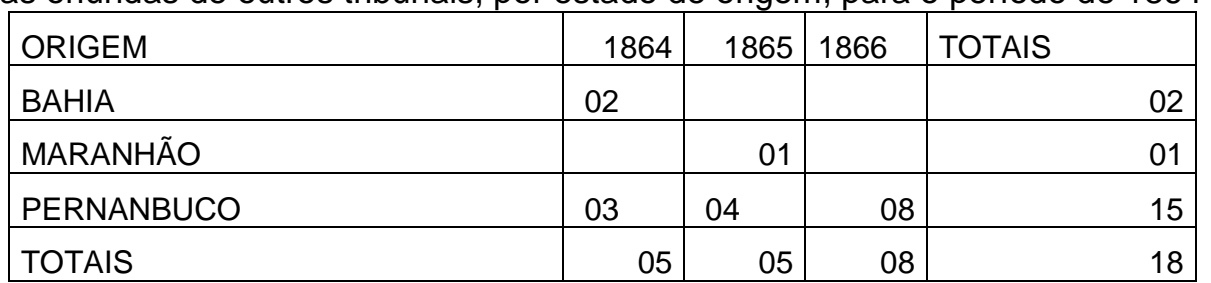

Fonte: AN, Código do fundo MX. Seção de guarda: SDJ, SDJ031, os seguintes livros:

Livro de entrada de feitos na secretaria (1855-1867),

Registro de entrada de autos (1861-1866).

Outro livro encontrado foi o de Registro de Acórdãos para o período de 1858 a 1876 , onde constam unicamente os registros dos recursos de Revistas oriundos de outros tribunais, em um total bruto de 55, sendo 39 de Pernambuco, 12 da Bahia, 3 do Maranhão e 1 sem identificação. Os dados apresentam perspectivas diferentes se considerados 0 quantitativo de acórdãos para o período, que aproximadamente compreende todo o tempo ativo do tribunal como órgão de segundo grau. Pois, nos Livros de Entrada de feitos na Secretaria e no Registro de autos, foi possível constatar só entre as Revistas negadas para o período de 1861-1865 um total de 40. Essa disparidade de dados leva a conclusão que nem todos os acórdãos eram registrados, uma média aproximada de dois por ano.

Esses números são condizentes com encontrados no primeiro relatório de do Presidente José Inácio Vaz Vieira para o ano de 1856, onde o mesmo relata que pela a atividade administrativa do tribunal elaborou o Regimento interno de sua Secretária, aprovado pelo plenário e posto em funcionamento, em conformidade ao Regulamento 737. Naquele ano o tribunal procedeu 132 matriculas de comerciantes, sendo 45 brasileiros, 68 estrangeiros e 19 sociedades mercantis. Também foram procedidas as matrículas de 8 corretores, sendo 7 de fundos públicos e 1 de mercadorias. Foram 3 reabilitações e 1 moratória concedidas, além de 1 moratória negada. No âmbito do $2^{\circ}$. 
Grau de jurisdição, o tribunal julgou 87 apelações, entre estas, 83 das 96 propostas naquele ano, 71 embargos, 151 agravos destes sendo 8 cartas testemunhais, 22 agravos de instrução e 121 agravos de petição e não foi julgado nenhum revista. Neste relatório o presidente Vaz Vieira informa que ainda não recebeu os relatórios dos demais tribunais, excetuando a da Bahia, e por isso não era possível o relato completo, mas em razão da data, 8 de março de, preferiu não atrasar mais ${ }^{6}$.

\section{O relacionamento do Tribunal do Comércio com os outros órgãos do Império}

A Constituição Brasileira do Império instituiu o Poder Judicial definindo-o como um dos poderes do Império, todavia, a atividade jurisdicional não era seu monopólio, mas um exercício dividido com o Conselho de Estado responsável pelo contencioso administrativo. Mais grave, a sua submissão ao Poder Moderador através dos atributos constitucionais que constituíram uma supervalorização do poder imperial, levando a uma centralização das decisões culminando com o cerceamento das competências do Poder Judicial, inclusive, compreendendo nas atribuições do Poder Moderador a definição das competências dos órgãos do judiciário. Essa constatação levou Rosalina Corrêa de Araújo a chamá-lo de poder proscrito e a verificar que o processo de evolução do Poder Judicial é a luta pela sua autonomia e independência ${ }^{7}$.

Essa busca pela autonomia e independência da atividade jurisdicional mostrou-se como um objetivo dos bacharéis e para o qual se desenvolveu estratégias, conforme se verificou no capítulo I, e pode ser observada no parecer exarado por Eusébio de Queiroz em resposta a consulta formulada pelo então ministro da justiça Nabuco de Araújo ao seu projeto de reforma do Tribunal de Comércio, que passou a vigorar em 1855, e um dos pontos atacados foi a redação do dispositivo que previa que em última análise, nas hipóteses de julgamento das exceções de incompetência, os conflitos de competência deveriam ser decididos pelo Presidente da Província. Para Eusébio, esta subordinação mostrava-se odiosa e contrária aos ditames da independência do judiciário ${ }^{8}$.

Todavia, as questões relativas às competências dos juízes continuavam a ser decididas em últimas instâncias pelo Executivo, conforme se verifica no comunicado destinado ao tribunal do Comércio do Maranhão:

\footnotetext{
${ }^{6}$ IHGB. Pecúlio Comercial. Lata 379, Livro 1, p. 289-291.

${ }^{7}$ Araújo, Rosalina Corrêa de (2004). O Estado e o Poder Judiciário no Brasil, 2ª Ed., Rio de Janeiro, Lumen Juris, p. 31-50.

${ }^{8}$ IHGB, lata 379.01, p. $22-27$.
} 
Rio de Janeiro, 10 de setembro de 1870.

IImo. e Exm. Sr. - A sua Magestade o Imperador foi presente o officio de 20 de novembro de 1869, no qual o presidente interino do tribunal do commercio d'essa província consultou ao governo imperial - "se é lícito ao deputado commercial, que nem é suspeito, nem está legalmente impedido, negar-se a votar matéria da competência do tribunal, sujeita ao seu conhecimento e regularmente instruída, a pretexto de querer proceder syndicancias secretas; e no caso negativo quaes as providencias que deve tomar o presidente do tribunal."

E o mesmo Augusto Senhor, tendo ouvido a secção de justiça do conselho d'estado, com cujo parecer se conformou por sua immediata resolução de 24 de Agosto ultimo, houve por bem mandar declarar a V. Ex. para fazer constar áquelle magistrado, que em todos os casos de jurisdicção administrativa, pedindo o deputado commercial espaço para examinar papeis e informar-se, se deve, ad instar do que dispõe o art. 45 do decreto n. 1599 do 1‥ De Maio de 1855, adiar a decisão para a conferência seguinte, porque muito importa à justiça o conhecimento da causa; e que, recusando-se elle a julgar a questão, depois de findo aquelle prazo, deve ser substituído e responsabilizado pelo crime previsto $n$

A art. 159 do Código Criminal.

Deus guarde a V. E. - Barão de Muritiba.

Sr. Presidente da Província do Maranhão9.

A falta de garantia de inamovibilidade, e a possibilidade de suspensão das atividades dos magistrados pelo imperador, apresentavam como forma de pressão possível de ser exercida sobre estes, isto se verificou na remoção do desembargador Antonio Manuel Fernandes e, de forma mais gritante, no caso do desembargador Albino José Barbosa d'Oliveira, quando após o julgamento do já referido caso Mauá X Astley, Wilson \& Cia houve uma consulta ao desembargador da Relação da Corte José Emídio dos Santos Tourinho, pelo visconde de Rio Branco (José Maria da Silva Paranhos), sobre as conseqüências de uma aposentadoria forçada para desembargador. Neste caso, como já se abordou, terminou com a remoção dos dois desembargadores e a dispensa do presidente do Tribunal do Comércio de seu cargo, através do discricionário ato do Ministro da Justiça, em confirmação da falta de independência do Poder do Judiciário.

Insatisfeitos com o desfecho imposto pela ação política, os desembargadores buscaram fora das estruturas administrativas do Poder Judiciário algum canal para a mostra do descontentamento. Para tanto, a forma escolhida por ambos foi a do envolvimento da opinião pública e dos políticos. O desembargador Antonio Manuel

\footnotetext{
${ }^{9}$ Fonte: Revista do IOAB, v. VII, Tomo 2, p. 100-101.
} 
Fernandes publicou o texto que denominou "Protesto por ocasião de ser destituído do Tribunal do Comércio da capital do Império e removido para a relação do Maranhão e os artigos e correspondências, a que este protesto deu logar; offerecido ao corpo legislativo do império e ao público e ao público em geral', Rio, $1862^{10}$.

Também buscou uma publicação o desembargador Albino José Barbosa d'Oliveira, a fim de tornar público e envolver outros personagens no evento, veiculando uma carta aberta pelo Jornal do Comércio, na íntegra:

\section{ALBINO JOSÉ BARBOSA D'OLIVEIRA \\ "Quamquam animus meninisse horret, Luctuque refugit, Incipiam."}

Em pais de publicidade e discussão todos devem ter a coragem de seus atos, mas o Sr. Saião, esperando o encerramento da câmaras para realizar um projeto no qual, já se rosnava desde de julho, deu provas nefanda cobardia, incongruente com o caráter audacioso, que ostenta.

Que o ato foi atentatório da divisão e independência dos poderes é da mais intuitiva evidência: não discutirei porém, esta questão, inútil em um pais em que o executivo é de fato onipotente: deixo-a para os nobres representantes da nação, não para a impossível responsabilidade, mas ao menor para a censura constitucional...

Neste país o governo só tem poder para duas cousas: 1‥ Para dar honra e vergonha aos que não têm; $2^{\circ}$. Para tirar a honra e a vergonha aos que têm.

No primeiro caso, a despeito das honras a opinião ri-se... E o mesmo acontece no infelizmente no segundo, quando o governo, descendo da alta posição que Ihe reservou a Constituição, e tornando-se capanga de algum improvisado figurão, abaixa-se a ponto de apanhar lama para atira-la sobre vultos respeitáveis.

Com efeito todas as circunstâncias, que desafiarei se for necessário, revelam que o fim do $\mathrm{Sr}$. Saião foi unicamente sacrificar à vingancinha de alquém os três juizes que tiverão a infelicidade de desagradar-Ihe no Tribunal do Comércio.

Se foi esse o motivo, o ato do Sr. Saião foi mais que um crime... foi uma vileza!

E se foi para influir de um modo mais eficaz sobre a decisão dos pleitos pendentes... oh! Nesse caso o ato do Sr. Saião está abaixo de toda a preciação.

Não permita Deus que fossem essas as causas de tão imprudente medida! Eu o desejo por honra de meus pais. Dos meus dois ilustres colegas, enxotados, como eu do Tribunal do Comércio, um já

\footnotetext{
${ }^{10}$ Oliveira, Conselheiro Albino José Barbosa de (1943). Memórias de um magistrado do Império. Revista e anotada por Américo Jacobina Lacombe, São Paulo: Companhia Editora Nacional, p. 88.
} 
discutiu nobremente os seus direitos pela imprensa, e o outro, fá-loá quando o entender conveniente. Eis-me pois sozinho diante dos Srs. Ministros, meus bons amigos, que me apertavam a mão, e alguns dos quais me visitavam, tratando-me até com familiaridade.

Eia, Srs. Ministros! A minha dignidade de homem e a minha respeitável posição de magistrado exigem uma explicação a meu respeito diante da câmara e diante do país.

Sou magistrado a trinta anos, desembargador há vinte: o meu caminho foi sempre semeado de flores, a minha carreira uma série de triunfos; recebi sempre as mais honrosas manifestações dos subalternos, dos iguais e dos superiores; fui sempre muito rico, porque as minhas aspirações nunca se elevaram além de minhas posses, e quando em 1847 uma aliança matrimonial, fazendo a minha felicidade doméstica, me constituiu também senhor de uma boa fortuna, sucessivamente aumentada por volumosas heranças, julquei-me acima da malivolência e até da calunia mesmo para os incrédulos, por que não dão nada pela honra dos pobres.

As $\mathrm{o}$ ato de 14 de setembro de 1861, desiludiu-me, e com surpresa e dor conheci e conheceu todo mundo que a seta vinha hervada!

A que motivo pois deverei eu atribuir semelhante destemperamento? Eia! Sr. Saião! Qualquer crime, ou mesmo falta, por pequeno que seja, que eu tenha cometido, quer na vida privada, quer na pública; quer como filho, esposo, pai, parente ou amigo, quer como cidadão em todos os atos da vida civil, e principalmente como magistrado: eia! Venha tudo a discussão.

Se eu sou hipócrita, arranque-me a máscara, e por bem da moralidade não consinta que eu goze de apanágios só devidos à virtude: mas, se eu sou um homem de bem, como diz a consciência: se mereço a estima de tantos cidadãos conspícuos, que afluíram à minha casa, aturdidos do destampatório ministerial e tantos outros, que das províncias me escreveram indignados pela tal celebreira, com que direito e para que fim veio o governo tão cruelmente molestar-me?

Ouçam - Havia o Sr. Saião dito no senado que sendo a magistratura respeitável em sua quase totalidade, tinha raras porém tristíssimas exceções, as quais S. Exa. Prometeu fulminar dentro da órbita da constituição.

Passou-se quase um ano, e o Sr. Saião só fulminou o tribunal de que fazia parte.

Isto exige uma explicação categórica, e o público tem direito a saber se há alguma relação entre aquele dito e este fato.

Espero que os nobres representantes da nação, mormente os que me conhecem (e são quase todos), chamem a contas o Sr. Ministro da Justiça e seus colegas, que muito sinto ver envolvidos neste desagradável episódio, porque lhes votava sincera estima, e Ihes supunha, a par de outras qualidades, juízo e consenso.

A minha questão é só com o ministério, de quem espero lealdade, sem a qual não há discussão possível.

Cá estou na tribuna universal, da qual, ou hei de ser expulso coberto de ignomínia, e convencido de crimes, ou hei de deixa-la (e Deus o 
há de permitir) radiante de júbilo e repetindo triunfante as palavras do venerando Simeão: Nunc dimittis servum tuum, Domine.

Dando expansão aos sentimentos que me abafam, Sr. Redator tenho a honra de ser seu, etc.

S. C. 9 de maio de $1862^{11}$.

Albino José Barbosa de Oliveira.

Deve ser destacado que, na verdade, quem primeiro alçou a questão para fora dos limites do fórum foi o próprio barão de Mauá, em discurso proferido no Senado e de repercussão em toda a sociedade brasileira e mesmo no exterior:

[...] É hoje desgraçadamente um fato reconhecido no Brasil e fora dele, que algumas decisões no Tribunal do Comércio não estão caracterizadas pelos princípios da retidão e imparcialidade.

[...] Ultimamente um processo de maior transcendência foi decidido com a mais revoltante injustiça [...].

Consoante o texto do próprio desembargador Albino, o objetivo era travar uma discussão em público com o ministro responsável pelo ato de destituição, embora o ato estivesse cristalizado e improvável qualquer possibilidade de reverte-lo. Sem nos esquecer-mos, conforme já mencionado (V. 4.1), que a intenção do desembargador em questão sempre foi servir na Relação do Maranhão e a designação para o Tribunal do Comércio um pedido do Conselheiro Nabuco, então no Ministério da Justiça. Além, de ter atribuída, repetidas vezes, a responsabilidade do ato ao imperador em proteção ao barão de Mauá, embora contraditório ao exarado em suas memórias, a disputa com o ministro era mais coerente.

O texto surtiu o efeito desejado, pois, a discussão tomou vulto no parlamento quando da apresentação dos relatórios ministeriais. A oposição passou a atacar tais relatórios obrigando o ministro Sayão Lobato a tomar a tribuna para defendê-lo e o fez ponto a ponto. Nesta defesa deixou-se claro o uso da discricionariedade do executivo em busca do principio da eficiência do serviço público e centrando a discussão unicamente na questão da legalidade, portanto, afastando o nefrálgico ponto da imparcialidade dos julgadores, conforme descrevemos em alguns trechos expressivos:

Sayão Lobato - As razões são óbvias, compreendi que o bem do serviço exigia do pessoal do Tribunal do comércio dessa Capital, e porque tinha a faculdade de deliberar e resolve-la, assim o pratiquei. [...] e cumpre, entender, que, sendo o princípio regulador o melhor desempenho do serviço público, este tem uma escala ascendente,

\footnotetext{
${ }^{11}$ Ibidem, p. 100-103.
} 
tem sua natural gradação; tal individuo presta bom serviço, tal outro presta-o melhor; e por que razão não se há de preferir o melhor ou o ótimo, se o houver?

Saraiva - V. Ex. atacando a honra dos magistrados, não tem coragem de exibir perante $o$ parlamento os motivos que determinaram o ato.

Zacarias - Foram os publicados no 'Jornal do comércio'.

Saraiva - V. Ex. se há de arrepender de ter injuriado a honra alheia, [...]

Bandeira de Melo - [...] e demais, a retirada desses membros do Tribunal do Comércio não importa a idéia de que são menos dignos.

Saraiva - Mas importam as circunstâncias que a acompanhavam [...] Bandeira de Melo - Os motivos que determinaram o nobre ministro a praticar esse ato the pertencem. Não podemos chama-lo a discussão.

Zacarias - Pertencem ao público.

Bandeira de Melo - Não pertencem, pertence ao público somente a legalidade; não tem que dar à câmara satisfação dos motivos que o determinaram (aplausos) porque de outra maneira não era governar ${ }^{12}$.

Para além da demonstração da ascendência do executivo sobre o judiciário e a repercussão da ação de outros órgãos na vida administrativa ou jurisdicional do tribunal do comércio, como qualquer outro órgão da estrutural estatal, a carta do desembargador Albino apresenta-se como um documento de relevância para demonstração e confirmação de circunstâncias da organização social da época imperial.

Primeiro destaca-se falta de noção de independência, à medida que essa é reclamada através de outros órgãos que reproduzam a interferência para corrigir a anterior.

Segundo, visível um grau de confusão entre via pública e privada, sendo argüido se a transferência ocorreu por falta na atividade profissional, na conduta social ou familiar. Práticas concepções do Estado romano, que a exceção do Período régio que se marca por uma confusão conceitual com a fusão entre o público e o privado $^{13}$, pode-se verificar a dificuldade de aceitar uma mera distinção entre público e privado como uma separação entre o que é do Estado e o interesse e utilidade particular, de forma que a ascensão às funções públicas e o exercício do poder de decisão política elou jurídica está na base dessa indistinção.

\footnotetext{
${ }^{12}$ Fonte: Anais da Câmara de 1862, sessão de 20 de maio.

13 "As grandezas de Roma era propriedade coletiva da classe governante e do grupo senatorial dirigente; assim também cada uma das milhares de cidades autônomas que formavam o tecido do Império era coisa dos notáveis locais". (Duby, Georges e Ariès, Philipe (org.) (1990). História da vida privada, São Paulo: Companhia das Letras, p. 103)
} 
Terceiro, temos a confirmação da tese esposada pela demonstração de Schwartz ${ }^{14}$, em que os magistrados procuravam se inserir na sociedade através do casamento com membros de famílias abastadas, respaldados no status inerente ao cargo e possibilitador de uniões familiares em atendimento a interesses recíprocos. A indicação para os cargos público destinavam-se à aqueles que fossem exemplo de bônus pater famílias, abastados. Como notória na história de Roma, a função pública é motivo de notoriedade e destaque pessoal e o que o Estado despreza é motivo de desprezo e esquecimento $^{15}$.

Quarta, a condição econômica como um patamar capaz de colocar a pessoa acima de suspeitas e livres de acusações classificadas, nesta condição, como mesquinhas ou obra da inveja, ou como se pode encontrar em Cícero (De oratore, 2, 52, 209) "a inveja segue atrás da glória - post gloriam invidiam segui”.

Pois "levar a vida política" - ou "exercer funções públicas" - não constituía uma atividade especializada: era a realização de um homem plenamente digno desse nome, de um membro da classe dominante - que se considerava apenas humana -, de uma pessoa privada ideal; não ter acesso a cargos públicos, à vida política da cidade equivaleria a ser mutilado, homem de baixa condição. ${ }^{16}$

Quinta, a certeza de determinados bacharéis que estão acima de suspeitas e grau de conhecimento técnico superior, qualquer menção no sentido contrário é tomada como uma ofensa a sua dignidade e de toda a classe, reduzida nesta 'elite' profissional. ${ }^{17}$

O direito julgado no Tribunal do Comércio foi amoldado pelo pensamento dos bacharéis através da interpretação dada pelos desembargadores responsáveis pela elaboração dos relatórios postos em votação. A prática do tribunal é pautada na lógica do positivismo jurídico, limitando-se a aplicação da lei sem interpretação que leve a uma construção ousada ou diversa da então dominante.

Esta interpretação representa sempre o fruto da formação uniforme imposta aos bacharéis, legitimada no passado histórico e, na presença da mínima possibilidade de vacilo ante a interpretação a ser dada a matéria era levada ao Poder Moderador através

\footnotetext{
${ }^{14}$ Schwartz, Stuart B. (1979). Burocracia e sociedade no Brasil colonial - A Suprema Corte da Bahia e seus juízes: 1609-1751. Tradução de Maria Helena Pires Martins, São Paulo: Perspectiva, p. 137-152.

15 "A dignidade se adquire, aumenta-se e pode-se perder. Exilado, Cícero se desespera: sua dignidade desapareceu, ele não é mais nada; chamado de volta a Roma, recebe novamente a dignidade". (Ibidem, p. 109).

${ }^{16}$ Ibidem, p. 113.

17 "A realidade política estava na cooptação: o clube que era o Senado decidia se um homem tinha o particular perfil social que o tornava admissível em seu seio e se traria sua cota ao prestígio coletivo que os membros desse clube dividiam entre si." (Ibidem, p. 103)
} 
do Conselho de Estado - como pode ser visto na Ata do Conselho, Seção da Justiça de maio de 1854, na qual, para suprimir dúvidas do Tribunal do Comércio, é dada a interpretação a ser empregada nos artigos 847, 848 e 900 do código Comercial - ou mesmo ao próprio Poder Executivo, como no caso da dúvida acerca da possibilidade de se criar sociedade em comandita dividida por ações, como adotado pelo barão de Mauá para a constituição do Banco Mauá \& Mc Grecor, em que se tomou a opinião do próprio ministro da justiça para se decidir sobre a sua possibilidade, em discussão de se arrastou e impôs o resultado no parlamento. (Guimarães, 1997).

Precária a independência do Poder Judicial com os seus integrantes sujeitos a vontade e abusos diversos, culminando em exercício hermenêutico limitado e tímido, presente a permanência de consultar ao executivo a inteligência do texto. Os Avisos ministeriais tinham a força de interpretação autêntica das normas ${ }^{18}$, para Vieira Ferreira (1937, p. 51) funcionava quase como os rescriptos do império romano. Jean- Pierre Dedieu destaque que a submissão do juiz á lei representa um esforço da doutrina do século XIX:

La ley humana no era entonces um imperativo de obligatorio cumplimento. Definida como el conjunto de lãs normas de derecho inventadas por los hombres, no pasada de ser la plasmación del modo habitual de hacer lãs cosas em uma sociedad concreta. Indicaba pautas, sin más. El juez no tênia ninguna obligación de era seguirla, em algunos casos tênia incluso el deber de no cuplirla. Se guiaba por ella em todo lo posible, por la incluso el deber de no cumplirla. Se guiaba por ella em todo lo posible, por la sencilla necessidad de garantizar a los usuários um mínimo de seguridad jurídica; pero en cada caso tênia que combrobar antes que la puesta em prácticas injustas. El juez no se gobernava por la ley, sino por la justicia; y la justicia no era de los hombres, sino de Dios. O sea, que el juez, lejos de ser el mero "portavoz de la ley" em que lê quisieron transformas los teóricos del siglo XIX, $[\ldots]^{19}$.

O controle do poder de dizer o Direito aplicado pelo Tribunal do Comércio, como em todos os outros tribunais, restava garantido através desse sistema de treinamento dos bacharéis, sistemática dos procedimentos, controle dos julgamentos pelos magistrados mais graduados - os desembargadores - e, no caso de falha nesta teia jurídica, em palavra final o controle era remetido ao Ministro da Justiça para dizer qual a interpretação a ser procedida ou, ainda, no caso concreto determinado pela Seção de Justiça do

\footnotetext{
18 Pelos preceitos constitucionais configurava atribuição da Assembléia Geral os atos de fazer leis, interpretar, suspende-las e revoga-las. (art. 15, 8․). (Grifei).

${ }_{19}$ Dedieu, Jean-Pierre (2005). "La muerte del letrado". In: Pérez, Francisco José Aranda (Coord.). Letrados, juristas y burocratos em la Espanha Moderna, Cuenca: La Universidade de Castilha-La Mancha, p. 481-482.
} 
Conselho de Estado, quando provocado através de recursos processuais. Isto pode ser constatado no recurso proposto pelo fiscal do Tribunal do Comércio da Capital, para a revisão da sentença de Reabilitação do banqueiro falido Antônio José Alves Souto. Nesta sentença, o tribunal entendeu incidir o artigo 868 do Código Comercial, enquanto o fiscal pugnava pela aplicação do artigo 7ํ․ Do Decreto 3.309 de 20/SET/1870. O Conselho confirmou a decisão do tribunal, por entender que a falência ocorrerá 60 dias antes da vigência do decreto em destaque ${ }^{20}$.

O direito julgado no Tribunal do Comércio também sofria um controle através de mecanismo de pressão social - a imprensa -, como pode ser observado no caso do julgamento do sinistro do Vapor Rio Negro, cujo provocou tremendo estardalhaço. (IHGB, Lata 376, pasta 2). Todavia, maior celeuma causou o julgamento realizado pelo Juiz Especial do Comércio da Primeira Vara da Capital, decidindo que a clausula compromissória $^{21}$ de arbitragem não impunha obrigatoriedade de cumprimento. Esta decisão foi tida como a decretação do fim da arbitragem e sucederam-se os artigos censurando a decisão, pelo Diário Mercantil do Rio de Janeiro, no. 147, 148, 150, 151, 152, 157 de 1857, alternando-se na autoria destes José Caetano, José Inácio Silveira da Mota, Teixeira de Freitas. Como se pode observar, escreviam no jornal os juristas formadores de opinião e autores das leis emitidas pelo Império.

\section{Conclusão}

Chegado o momento, a óbvia conclusão nos mostra que a falta de autonomia do Tribunal do Comercio permitiu a intervenção de outros poderes do Império na sua organização interna e na atuação jurisdicional, uma vez que permitia a pressão sobre seus membros. Outra vertente conclusiva diz respeito às pressões políticas de outras instituições e da imprensa sobre os juízes, que interessados em alavancar a carreira jurídica e manter abertas as possibilidades de acumular experiências no campo político, para as quais, necessário a manutenção de uma rede de sociabilidade. O direito julgado no tribunal estava aparentemente amarrado ao formalismo e subordinado ao tecnicismo da expertise jurídica, todavia, a técnica servia para camuflar determinadas tendências e interesses destinados.

\footnotetext{
${ }^{20}$ IHGB, Lata 371, Pasta 31.

${ }^{21}$ Tal clausula de previsão no artigo 469 do Regulamento 737, significa que as partes se comprometeram a levar a contenta para julgamento por árbitro nomeado e impõe a obrigatoriedade de cumprimento da decisão imposta pelo mesmo.
} 


\section{Referências Bibliográficas}

\section{a) Fontes primárias}

ARQUIVO NACIONAL. Fundo/Coleção: Códices de Poder Judiciário. Data-limite: 1763 a 1954. Código do fundo MX. Seção de guarda: SDJ, SDJ031.

Conteúdo:

Protocolo de Remessa de apelações (1854-1855)

Guia de andamento de apelações comerciais embargo e registros (1855-1860)

Registro de entrada de autos (1861-1866)

Livro de inventário dos autos de apelações (1855)

Entrada dos feitos na secretaria judicial (1855-1867)

Distribuição dos feitos aos juizes adjuntos (1855-1873)

Registro dos acórdãos (1858-1876)

Oliveira, Conselheiro Albino José Barbosa de (1943). Memórias de um magistrado do Império. Revista e anotada por Américo Jacobina Lacombe, São Paulo: Companhia Editora Nacional.

Tribunal de Justiça do Estado do Rio de Janeiro. Catálogo de desembargadores da Justiça do estado do Rio de Janeiro (1751-1991).

Tribunal de Justiça do Estado do Rio de Janeiro. (2005). Departamento Geral de Arquivo. Gestão de Documento. Criação do Tribunal da Relação do Rio de Janeiro - 1751. Exposição Historia do Tribunal de Justiça.

\section{b) Bibliografia}

Araújo, Rosalina Corrêa de (2004). O Estado e o Poder Judiciário no Brasil, 2ª Ed., Rio de Janeiro, Lumen Juris.

Beltrán, Jesús Manuel Gonzáles (2005). “Um ejército armado de pluma y papel sellado. Uma aproximación a la burocracia del siglo XVIII". In: Pérez, Francisco José Aranda (Coord.). Letrados, juristas y burocratos em la Espanha Moderna, Cuenca: La Universidade de Castilha-La Mancha. 
Dedieu, Jean-Pierre (2005). “La muerte del letrado". In: Pérez, Francisco José Aranda (Coord.). Letrados, juristas y burocratos em la Espanha Moderna, Cuenca: La Universidade de Castilha-La Mancha.

Duby, Georges e Ariès, Philipe (org.) (1990). História da vida privada, São Paulo: Companhia das Letras.

Garcia, Pedro Vega. "Prólogo". In: Smith, Karl; Kelsen, Hans (1993). La defensa de la constitución, Madri: Tecnos.

Neder, Gizlene (1998). "Coimbra e os juristas brasileiros”. In: Revista Discursos Sediosos: crime, Direito e sociedade, Rio de Janeiro, ano 3, n. 5-6, p. 195-214.

Neder, Gizlene. (2003). "Cultura política, prática ideológica e formação de servidores públicos no Brasil”. In: Achegas net: revista de Ciência Política. www. Achegas.net, acessado em 03/11/05.

Schwartz, Stuart B. (1979). Burocracia e sociedade no Brasil colonial - A Suprema Corte da Bahia e seus juízes: 1609-1751. Tradução de Maria Helena Pires Martins, São Paulo: Perspectiva.

Simões, Teotônio (1983). Os bacharéis na política - a política dos bacharéis. Tese (Doutorado em Ciências Sociais) - Universidade de São Paulo, São Paulo.

Weber, Max (1999). Economia e sociedade. Tradução de Regis Barbosa e Karen Elsabe Barbosa, Brasília: UnB, 2. v.

Vieira, Rubenita (1985). O Tribunal do Comércio: Modernização e Imobilismo (18511889). Dissertação (Mestrado em História) - Universidade Federal do Rio de Janeiro, Rio de Janeiro.

Recebido para publicação em março de 2012.

Aprovado para publicação em abril de 2012. 